\title{
Beyond Drag and Drop: Balancing Experience and Innovation in Online Technical Communication Course Development
}

\section{Jessica Livingston, Rose-Hulman Institute of Technology}

Jessica Livingston is an associate professor of English at Rose-Hulman Institute of Technology. She received a B.A. from the University of Georgia, an M.A. from the University of Kentucky, and a Ph.D. from the University of Florida. Her areas of interest include engineering communication and pedagogy, the intersections of gender and work in a global economy, and documentary film.

\section{Dr. Sarah Summers, Rose-Hulman Institute of Technology}

Dr. Sarah Summers earned her PhD in Rhetoric and Composition from Penn State University and joined the RHIT faculty in 2014. Her work focused on writing in the disciplines, particularly at the advanced undergraduate and graduate levels. She teaches courses in writing and engineering communication, including technical and professional communication, intercultural communication, digital writing, and grant writing.

\section{Mary Jane Szabo, Rose-Hulman Institute of Technology}

Mary Jane (Janie) Szabo is currently pursuing her PhD in Curriculum and Instruction with an emphasis in Educational Technology from Indiana State University. In her current role as an Instructional Designer at Rose-Hulman Institute of Technology, she collaborates with faculty on developing face-to-face, hybrid, and online courses. Janie also coordinates and provides training and support for the campus Learning Management System, Moodle, and Multimedia System, Panopto. 


\section{Beyond Drag and Drop: Balancing Experience and Innovation in Online Technical Communication Course Development}

Online learning is increasingly part of students' higher education experience. Recent reports, including the New Media Consortium Horizon Report [1] and The Babson Survey of Online Learning [2] report an increase in hybrid, online, and multimedia learning. Redesigning courses for these new environments gives faculty members opportunities to rethink their pedagogical practices and the way they deliver course materials to students. When adapting a course to an online format leveraging the learning management system (LMS), it's tempting to rely on existing pedagogies first and then integrate technology into that tried-and-true structure. Yet, a strictly pedagogy-first attitude assumes that technologies are neutral and that any practices can be simply mapped onto any technologies to serve any student. But merely dragging and dropping face-to-face content into an online course misses opportunities for the multiple means of representation and customized learning experiences that technology can afford.

To help faculty take advantage of features that enhance student learning and motivation, Rose-Hulman Office of Learning and Technology offers a paid summer course development workshop for faculty who are designing online or hybrid courses. One focus of the workshop is to help faculty members create accessible courses using Universal Design for Learning (UDL) principles. In this paper, we describe the transition of our required writing course, Technical and Professional Communication (Tech Comm), into online and hybrid formats. Specifically, we focus on how UDL principles helped us rethink our classroom pedagogies and created opportunities for us to develop new, more accessible course materials. Our course, like many technical writing courses, includes students from multiple disciplines who are often resistant to taking a required course offered by faculty outside their major. We found that a UDL framework enables students to engage with course content in multiple ways, which lessen student resistance and increase students' confidence in their professional skills.

In the sections that follow, we first provide a literature review of UDL and the ways that accessibility extends beyond its typical association with disability. Using UDL principles as our guiding framework, we then provide examples of how we used LMS features make our courses more engaging, accessible, and flexible for diverse groups of students while still meeting established outcomes for writing and professional development. Specifically, we discuss an online course designed and implemented by Professor Sarah Summers and a hybrid course designed and implemented by Professor Jessica Livingston, with guidance from Instructional Designer Janie Szabo. We conclude by highlighting the recursive nature of these changes and explaining the ways our online course development has influenced the design of our face-to-face classrooms and assignments. 


\section{Beyond Accessibility: Universal Design for Learning}

In order to appreciate the UDL framework, it is important to review the three main principles, which address the what (recognition brain networks), the how (strategic brain networks), and the why (affective brain networks) of learning. CAST's 2011 UDL framework suggests that these three main principles and associated nine guidelines, shown in Appendix A [3], should result in resourceful, knowledgeable learners, strategic, goal-directed learners, and purposeful, motivated learners: "A key premise of UDL is that a curriculum should include alternatives to make it accessible and applicable to students with different backgrounds, learning styles, abilities, and disabilities and to minimize the need for assistive technology" [4]. The following statements explain each of the three main principles of the UDL framework:

- Principle 1 suggests representing information in multiple ways. For example, including video lectures with built in navigation through slides or captions.

- Principle 2 recommends integrating options for planning and composition. For example, providing varied forms of graphic organizers.

- Principle 3 promotes varying activities that increase interest and self-regulation. For example, integrating weekly reflective writing prompts.

Studies suggest that incorporating these principles into course design increases learning and engagement for all students $[5,6]$.

Despite these wide-ranging benefits, research about implementing UDL in science, technology, engineering, and mathematics (STEM) fields primarily focuses on accessibility, including the use of technology accommodations, due to Americans with Disabilities Act (ADA) and Web Content Accessibility (WCAG) requirements for online learning environments [7]. From the ASEE archive, one paper authored by Monemi, Pan, \& Varnado (2009) suggested the use of UDL for course design benefiting all learners: "Varied instructional methods using UDL are provided to engage students in the learning process throughout the quarter" [8]. However, Monemi et al. still noted that, "it was clear from the assessment results that using UDL concept helped greatly the students with limited ability, hard to grasp, slow learner or thinker" [8]. Thus, the focus remains on students with disabilities.

Our focus in this paper is to demonstrate the ways that UDL benefits all students in a course and creates opportunities for learning and engagement for students with a range of abilities and preferences. We view UDL not only as a way to incorporate ADA compliance but as an approach to course design accommodating all students. As we discuss in the following section, the benefits of UDL are especially important for our Tech Comm courses, which combine students from our various fields of study.

\section{UDL and Technical Communication}

Tech Comm is a required, upper-level writing course usually taken by students in their junior year. The course is based in the rhetorical tradition, which means that analyzing and adapting to a specific audience are central to the writing process. The course objectives, which are 
determined by the writing faculty and shared across all sections of the course, include writing in several genres, collaborating with teammates, and developing project management skills. Within these shared objectives, Tech Comm instructors have freedom to design their own courses and assignments. While some sections focus more heavily on research, for example, others focus on humanitarian engineering or usability. This flexibility made it possible for us to expand our course offerings to hybrid and online versions and to adapt course content to take advantage of these new formats.

There are several broad ways that the hybrid and online Tech Comm courses incorporate UDL principles. The first set of guidelines encourage instructions to offer students multiple means of representation. Using an LMS enables instructions to meet those needs in a variety of ways. Both courses offer alternative text for images displayed in the LMS and leverage HTML code to facilitate responsive design. The online course incorporated multiple means of media, including written text and screencasts, to deliver students announcements and updates for the asynchronous learning environment. Each of the courses provide options for comprehension by showcasing student examples and embedding or linking to online resources that complement the adopted textbook. In the following sections, we highlight these and other activities as they correspond to specific UDL guidelines and discuss their implementation and the changes we observed from our face-to-face courses.

\section{Options for Expression and Communication}

As participants in the course development cohort, we were introduced to the range of activities available in the LMS and encouraged to leverage a variety of these activities to meet UDL Principle 5: Provide Options for Expression and Communication. In a fully online course, this includes providing students with a variety of ways to communicate with me and each other and a variety of ways to compose. My [Prof. Summers] face-to-face course frequently relies on in-class discussion of models and in-class writing. Designing an online course presented me with an opportunity to communicate with students in new ways and to ask students to share their ideas across multiple media. While multimedia experiences are sometimes seen as distractions, pedagogical research reframes distraction as disruption--a way to embrace the changes that follow from new technology opportunities. For example, as Camplese and McDonald (2010) found when they designed courses that embraced these new pedagogical environments as welcome disruptions, not distractions, students "ask questions, provide resources, gain confidence, and interact in ways that shattered our previously established ideas about how a class should work" [9].

In Tech Comm, both the face-to-face course and the online course, students compose job application materials. The unit begins with students selecting and analyzing job advertisements and researching companies. In my face-to-face class, we brainstorm things students might want to find out about a company and list them on the board. Then, students work independently to 
research their chosen companies and submit a memo to me detailing their research. In my online course, rather than just list possible research questions or record a lecture, I created a short screencast of me researching a sample company. The video showed my computer screen as I navigated a company's website and explained to students what I was looking for as I clicked on each section. Following the screencast, students had two ways to communicate their findings. First, they participated in a brainstorming forum with their peers to discuss preliminary ideas about their job ads and their company research. After they had a chance to share ideas informally with peers, the students completed a more formal planning memo addressed to me using the Quiz feature. I read and responded to these memos, giving them feedback to shape their cover letters and resumes.

The LMS activity logs reveal that every student in the course viewed the video, and many students returned to the video later in the week--presumably as they were composing their memos. Providing multiple means of communication--both text-based instructions and the video--gave students more flexibility to learn at their own pace, revisit course ideas, and use my example as a model. In face-to-face discussions, students who are advanced enough in their job search would be ready to engage with the examples I provide, but many students may be more worried about finding the right job ad or company and not yet ready to research. The multimedia resource, which I plan to make available to my face-to-face students, gives students access to course examples exactly when they need them. Additionally, by giving students the opportunity to write about their ideas informally with their peers--rather than just asking a few students to share examples in class--each student had the opportunity to develop ideas before submitting a more formalized version to me. This additional writing option provided students with practice communicating their ideas and resulted in clearer, more complete memos.

In transforming a face-to-face course to a hybrid course, the central challenge is determining which activities are better suited for the LMS vs. the classroom. In the hybrid version of my [Prof. Livingston] course the graded course projects remained the same, but many of the activities that would take place during class time were moved to the LMS and a portion of the grade allocated for successful completion of them. These assignments are graded on a credit/no credit basis as an incentive for completion. If students complete the assignment according to the instructions, then they receive full credit. Generally, more than $90 \%$ of the class completes each assignment.

In the hybrid version of the course, students only meet 2 rather than 4 times a week and then complete work in the LMS in lieu of class for the other 2 days. I use in-class time for student presentations, workshops and conferences on drafts, as well as team meetings. In the LMS students review rhetorical principles and best practices and then assess sample documents. I selected these aspects of the course for the following pedagogical reasons: 1) to improve student 
retention of course concepts 2) to increase individual student accountability and 3) to improve the quality of the learning experience. Each discussion forum provides students with a prompt and sometimes a word requirement for responding:

\title{
Sample Student Policy Briefs Discussion Forum
}

\begin{abstract}
Read and evaluate discuss the sample student policy briefs. While you might find failures in audience accommodation, I want you to focus on what they do well as you prepare to write your own brief. In your post, identify 3 effective strategies in the sample student policy briefs for effectively accommodating readers, particularly a decision-making but non-technical specialist audience

This forum requires you to post before you can see other responses.
\end{abstract}

Add a new question

Discussion Identifying effective audience accommodation

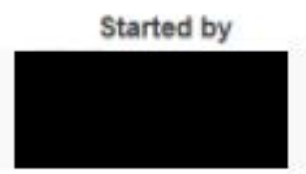

Last post

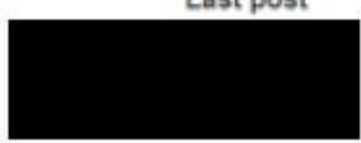

Often student discussions of course content in the face-to-face course were unsatisfactory. Many students did not contribute, and some of their comments tended to be nitpicky and/or argumentative rather than constructive. Furthermore, in course evaluations some students expressed that they did not have clear take-away points following the discussion of samples, and I observed that students sometimes inaccurately remembered the discussion, for example mimicking rhetorical strategies that were discussed as ineffective in class.

In the hybrid course, in the LMS students complete quizzes covering the course textbook, which introduces rhetorical principles and provides best practices. The quizzes are designed as a learning tool to reinforce important concepts rather than to test students' memory of them. Students have the option of repeating the quizzes as many times as necessary to earn $100 \%$. Because students have been resistant to reading the course textbook, I designed this new model provide a grade incentive for all of the students to skim the text at minimum for the answer to the quizzes to receive credit. To further reinforce the rhetorical principles, each module includes multimedia content, such as videos and external websites, which are embedded into the LMS when possible.

Each module also includes sample documents embedded as PDFs. Although the sample documents are imperfect, I select samples from the higher range of previous student work. Students assess the samples within a discussion forum which requires students to post their response before they can see other students' responses. After they have posted though, they can read their classmates responses and return to the forum when they are drafting and revising their own documents. In addition, after the student deadline for the forum, I send a wrap-up of the forum that includes key summary. This wrap-up is posted both in the forum itself and in the 
Announcements forum which automatically sends the message to the students' email account so that they receive the content even if they do not seek it out. The activity logs show that some students do return to the discussion forums as they are drafting their own documents.

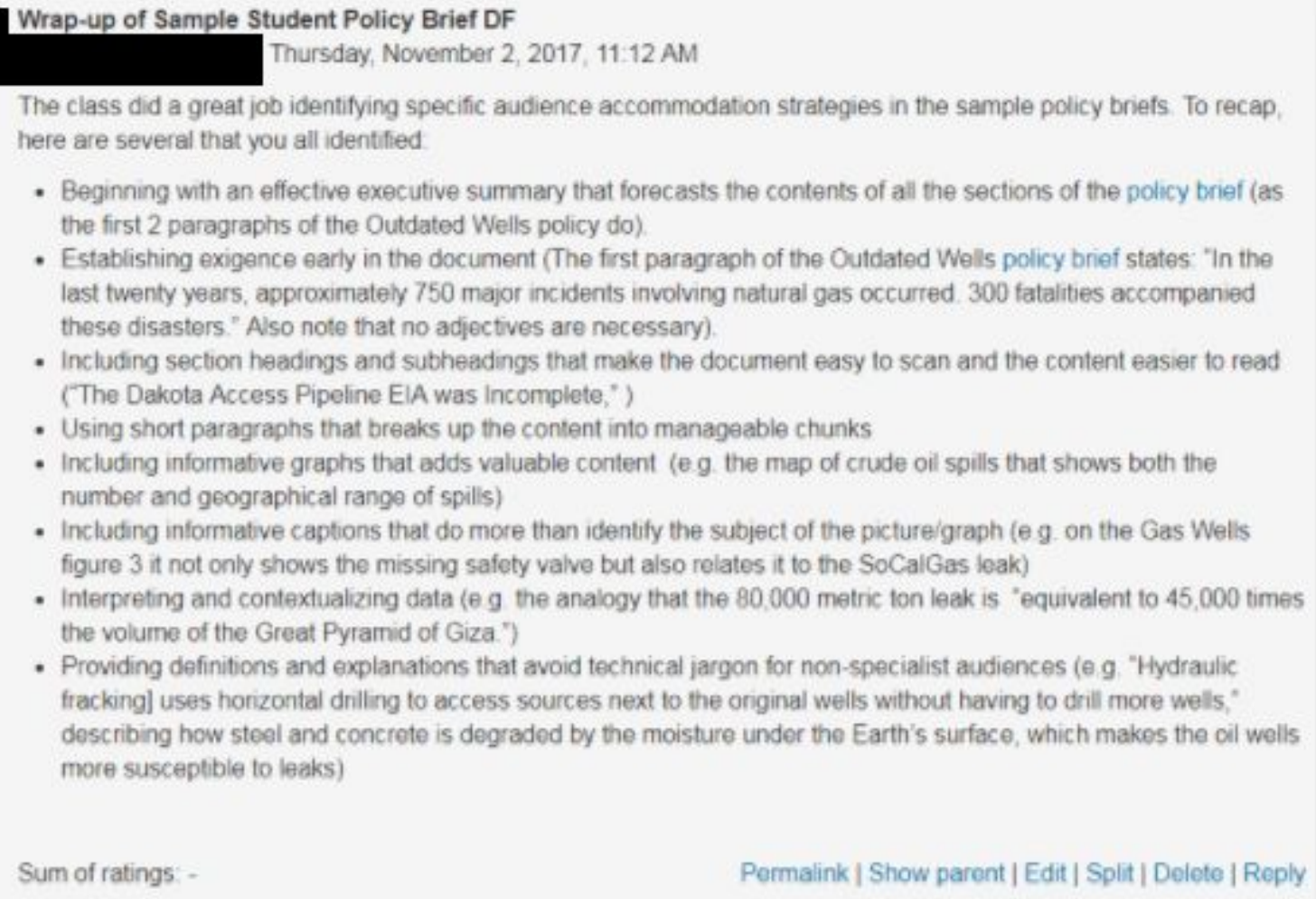

- Beginning with an effective executive summary that forecasts the contents of all the sections of the policy brief (as the first 2 paragraphs of the Outdated Wells policy do).

- Establishing exigence early in the document (The first paragraph of the Outdated Wells policy brief states: "In the last twenty years, approximately 750 major incidents involving natural gas occurred. 300 fatalities accompanied these disasters." Also note that no adjectives are necessary).

- Including section headings and subheadings that make the document easy to scan and the content easier to read (The Dakota Access Pipeline EIA was Incomplete,")

- Using short paragraphs that breaks up the content into manageable chunks

- Including informative graphs that adds valuable content (eg. the map of crude oil spills that shows both the number and geographical range of spills)

- Including informative captions that do more than identify the subject of the picture/graph (e g. on the Gas Wells figure 3 it not only shows the missing safety valve but also relates it to the SoCalGas leak)

- Interpreting and contextualizing data ( $\theta \mathrm{g}$ the analogy that the 80,000 metric ton leak is "equivalent to 45,000 times the volume of the Great Pyramid of Giza.")

- Providing definitions and explanations that avoid technical jargon for non-specialist audiences (e.g. "Hydraulic frackingl uses horizontal driling to access sources next to the original wells without having to drill more wells," describing how steel and concrete is degraded by the moisture under the Earth's surface, which makes the cil wells more susceptible to leaks)

The LMS provides students a different means of communication than that which is used in the classroom space. In the discussion forums, students are more professional and constructive than in the classroom, perhaps because their communication is written. Furthermore, student responses are more thoughtful and detailed than they would be in a class discussion. The more motivated students often make specific reference to course concepts in the textbook and apply the course concepts in their assessment of sample documents. Most importantly, all the students gain practice in rhetorical analysis and assessment contrary to the limited few that would in a classroom discussion.

\section{Options for Recruiting Interest}

Providing a variety of course media and options for communication can motivate students to complete activities and keep the course from seeming repetitive, but I [Prof. Summers] also wanted to encourage students to engage deeply with the course material. Engagement is a challenge in RH330 regardless of the format; as a required writing course, many students view it as less important than their engineering courses--just a box to check on the way to graduation. In my face-to-face classes, I design hands-on projects, including LEGO building projects and paper prototyping, to keep students engaged. Because hands-on collaborative projects would be 
difficult to facilitate online, I needed other ways to encourage students to engage with course content. I turned to the UDL guidelines for recruiting interest, including "optimizing individual choice and autonomy" and "optimizing relevance, value, and authenticity," as I designed the primary course project.

When I designed the online course, I decided to take full advantage of the online format and require that students who enrolled in the course also participate in an internship, co-op, or formalized research experience during the course. As a result, all of my students had professional experiences at the same time that they were learning about professional communication. The course assignments asked students to leverage these experiences. For example, in a face-to-face course in which not every student has had work experience, I give students generic workplace documents to analyze. Because the online course coincided with internships, students analyzed real documents from their own workplaces and labs. Students also received feedback on their portfolios from workplace mentors, and wrote professional emails to respond to real workplace needs. As a result, the course was tailored to students' individual experiences and had authentic ties to their professional lives, which reinforced the value and relevance of the course.

I also tailored the collaborative assignment to students' goals for the course to increase their sense of autonomy and the value of the course. In the introductory discussion board, I asked students to share what they hoped to learn from the course. Many of them included specific professional communication tasks, like making small talk in the office and creating a professional online presence. Because students wanted to work on these skills, I redesigned the collaborative project to ask groups of students to create webcasts on professional communication skills. As part of their projects, students did academic research and interviewed their workplace mentors. The flexibility of the online format allowed me to make changes as the course evolved to allow students to have control over some of the course outcomes and do authentic research that they believe will be valuable to their professional communication skills. As the figure below shows, the assignment encourages students to draw on their professional experiences and to adjust the assignment to meet their own goals and needs as a team: 


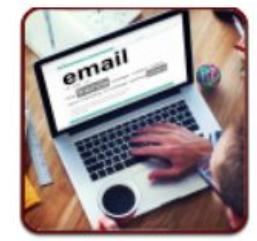

During Week 6 and Week 7 , you will work on your group project, which includes individual work (emails and an executive summary in Week 6) and a group-written, researched proposal (Week 7). I've grouped these weeks together, so that you have more flexibility for seeing all of the assignments. I have provided readings and tasks on a suggested schedule as well as suggested work days, but ultimately it is up to your team to work on the schedule that best accommodates your group as long as you meet both major assignment deadlines. Don't forget to keep meeting minutes and post them to your team dropbox (see Week 5) throughout the project.

\section{Objectives}

By the end of this project, you will be able to

- identify the conventions of professional documents including proposals and meeting documentation

- consider the role of the audience in professional communication and across genres

- describe a project, its value to an audience, and its rationale

- employ strategies for collaborative writing, speaking, and problem solving

Options for Executive Function and Self-Regulation

One of the challenges for both online and hybrid courses is not consistently seeing students in the classroom and being able to check in on their progress. Students must employ or develop self-regulation strategies to make appropriate progress in the course. As described in the UDL guidelines, courses should help students monitor their progress and develop strategies for self-reflection and self-assessment.

Both the online and hybrid courses include checklists that detail all the assignments that students need to complete as well as deadlines.

\section{Checklist}

- Read sample student policy briefs and post in the Sample Student Policy Briefs Discussion Forum

- Read ECM 19: "Revising" and 22: "Sentences" and complete the Week 9 Quiz

- Post to the Policy Brief Peer Review.

- Review a sample collaborative outline and draft your outline as a team

- Submit your team's policy brief draft in the discussion forum Policy Brief Peer Review, and then individually provide feedback to the draft which you are assigned

- Provide me with a link or file for your project management files in class

- Submit both a paper and electronic copy of your Policy Brief

- Complete a Team Evaluation 
Because students in a hybrid course have the additional challenge of monitoring their progress in both the LMS and in the classroom--e.g completing discussion forums online and bringing drafts to class when needed--I (Prof. Livingston) include a Calendar that includes both in the Syllabus. In addition, I also include a mini-calendar of the relevant weeks in each module so that students can keep track of their assignments without having to check multiple locations. Students also have the option to work ahead on their assignments.

\begin{tabular}{|c|c|c|c|c|c|}
\hline & Monday & Tuesday & Wednesday & Thursday & Friday \\
\hline $\begin{array}{l}\text { Week } \\
9\end{array}$ & $\begin{array}{l}\text { Public Briefing } \\
\text { Presentations }\end{array}$ & $\begin{array}{l}\text { Student Policy } \\
\text { Brief DF by } 11: 59 \\
\text { p.m. }\end{array}$ & & $\begin{array}{l}\text { Week } 9 \text { Quiz by } \\
\text { class }\end{array}$ & $\begin{array}{l}\text { Collaborative } \\
\text { outline due by } 5 \\
\text { p.m. }\end{array}$ \\
\hline $\begin{array}{l}\text { Week } \\
10\end{array}$ & $\begin{array}{l}\text { Draft due for peer } \\
\text { review by } 11: 59 \\
\text { p.m. }\end{array}$ & $\begin{array}{l}\text { Peer review } \\
\text { completed by } \\
11: 59 \text { p.m. }\end{array}$ & & $\begin{array}{l}\text { Project } \\
\text { Management files } \\
\text { in class }\end{array}$ & $\begin{array}{l}\text { Policy Brief due } \\
\text { by } 5 \text { p.m. }\end{array}$ \\
\hline Finals & $\begin{array}{l}\text { Team Evaluation } \\
\text { due by } 11: 59 \\
\text { p.m. on Sun. }\end{array}$ & & & & \\
\hline
\end{tabular}

Although the collaborative project in the hybrid course is the same as in the face-to-face class, student teams need to take more responsibility for meeting regularly when they are seeing each other in class less frequently than students in a face-to-face class. Therefore, guiding students project management practices becomes more important. In the hybrid course, the collaborative project includes several project milestones, such as a working bibliography and collaborative outline, that assist students in making progress and teach them how to create internal deadlines on a large-scale project.

Students also reflect and assess their project management, teamwork, and communication skills at the beginning and end of the collaborative project. Prior to forming teams, students take a personality test and reflect upon the results in a discussion forum, identifying their strengths as a team member, what roles they like/dislike to take in group projects, and possibly frustrations that they've had with previous team projects. Students can read other student's post before submitting a team member preferences form as well as returning to them when they are working in their teams. At the conclusion of the collaborative project, students assess the performance of their team and each member, considering what collaborative strategies they used successfully (e.g. shared planning, outlining, recording decisions and action items, using online tools, revising as 
team) and what they learned from their experience about project management, collaborative writing, leadership and/or teamwork. The prompt encourages honest and constructive feedback, stating that acknowledging mistakes and shortcomings (of yourself or the team as a whole) builds your ethos because it demonstrates conscientious reflection and the possibility for improvement in the future. Even though the team evaluation is a factor in determining individual teamwork grades, students are often honest in their reflections, taking responsibility for their own shortcomings.

\section{Conclusion}

In designing our Tech Comm courses with elements of the UDL framework, we have expanded our pedagogical practices and have provided our students with multiple means of representation, action and expression, and engagement. This experience has us re-evaluating our face-to-face classes, considering ways to implement elements of UDL in those courses as well as which activities in those classes might be more successful in the LMS.

I (Prof. Summers) have brought many of my online activities--like demonstrating to students how I would research a company--into my face-to-face course. More broadly, I've used my LMS page to be more transparent about course and assignment-level goals and objectives. In an online course, it's important to present those clearly to students in each unit to promote the self-regulation and reflection. I often discuss those objectives in my face-to-face course, but I've been more intentional about using the LMS to highlight them.

Similarly, I (Prof. Livingston) have incorporated several elements into my face-to-face classes, such as weekly checklists and Q \& A discussion forums. I use the discussion forums to have students apply course concepts which both prepares them for in-class discussions as well as increases their engagement from just speaking in class to writing as well. Based on the higher quality of work when assessing sample documents in the hybrid Tech Comm course, I am considering revising the structure of some of my other courses that require students to engage with non-fictional texts rhetorically to a hybrid format.

As these examples demonstrate, incorporating UDL principles goes beyond accessibility and even beyond online learning. Once we had practice applying these principles, we were able to see the ways that small pedagogical shifts and experiments can support engagement and learning for all of our students. 


\section{References}

[1] The New Media Consortium and the Educause Learning Initiative, The NMC horizon report: 2016 Higher education edition. [Online].

www.nmc.org/publication/nmc-horizon-report-2016-higher-education-edition/

[2] Babson Survey Research Group, 2015 online report card: Tracking online education in the United States. [Online].

https://onlinelearningconsortium.org/read/online-report-card-tracking-online-education-united-st $\underline{\text { ates-2015/ }}$

[3] CAST, Universal design for learning guidelines version 2.0. Wakefield, MA: Author, 2011.

[4] Burgstahler, S. E, Universal design in higher education. Cambridge, MA: Harvard Education Press, 2015.

[5] Smith, F. G, Analyzing a college course that adheres to the universal design for learning (UDL) framework. Journal of the Scholarship of Teaching and Learning, 12(3), 31-61, 2012.

[6] Scott, L. A., Temple, P., \& Marshall, D, UDL in online college coursework: Insights of infusion and educator preparedness. Online Learning, 19(5), 99-119, 2015.

[7] Wu, S. Accessibility, usability, and universal design in online engineering education, Paper presented at the meeting of American Society for Engineering Education, Seattle, WA, 2015.

[8] Monemi, S., Pan, W., \& Varnado, E, Project design principles and applications using Universal Design for Learning (UDL). Paper presented at the meeting of American Society for Engineering Education, Austin, TX, 2009.

[9] Camplese, C. W. and S. McDonald, "Disrupting the Classroom," Edge 5, no. 4, 1-19, 2010. [Online]. https://scholarsphere.psu.edu/downloads/70795771g 


\section{Universal Design for Learning Guidelines}

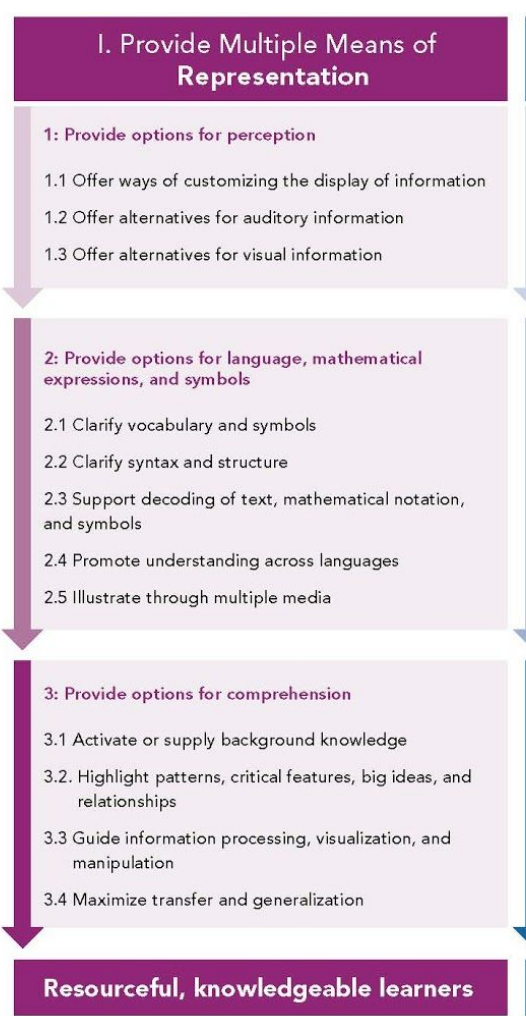

(2) CAST

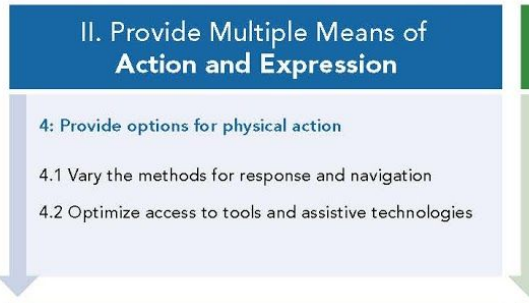

5: Provide options for expression and communication 5.1 Use multiple media for communication 5.2 Use multiple tools for construction and composition 5.3 Build fluencies with graduated levels of support for practice and performance

6: Provide options for executive functions

6.1 Guide appropriate goal-setting

6.2 Support planning and strategy development

6.3 Facilitate managing information and resources

6.4 Enhance capacity for monitoring progress

Strategic, goal-directed learners

\section{Provide Multiple Means of \\ Engagement}

7: Provide options for recruiting interest

7.1 Optimize individual choice and autonomy

7.2 Optimize relevance, value, and authenticity

7.3 Minimize threats and distractions

8: Provide options for sustaining effort and persistence

8.1 Heighten salience of goals and objectives

8.2 Vary demands and resources to optimize challenge

8.3 Foster collaboration and community

8.4 Increase mastery-oriented feedback

9: Provide options for self-regulation

9.1 Promote expectations and beliefs that optimize motivation

9.2 Facilitate personal coping skills and strategies

9.3 Develop self-assessment and reflection

Purposeful, motivated learners 